\title{
Synthetic Covalently Linked Dimeric Form of H2 Relaxin Retains Native RXFP1 Activity and Has Improved In Vitro Serum Stability
}

\author{
Vinojini B. Nair, ${ }^{1,2}$ Ross A. D. Bathgate, ${ }^{1,3}$ Frances Separovic, ${ }^{2}$ Chrishan S. Samuel, ${ }^{4}$ \\ Mohammed Akhter Hossain, ${ }^{1,2}$ and John D. Wade ${ }^{1,2}$ \\ ${ }^{1}$ Florey Institute of Neuroscience and Mental Health, University of Melbourne, Parkville, VIC 3010, Australia \\ ${ }^{2}$ School of Chemistry, University of Melbourne, Parkville, VIC 3010, Australia \\ ${ }^{3}$ Department of Biochemistry and Molecular Biology, University of Melbourne, Parkville, VIC 3010, Australia \\ ${ }^{4}$ Department of Pharmacology, Monash University, Clayton, VIC 3800, Australia
}

Correspondence should be addressed to Mohammed Akhter Hossain; akhter.hossain@florey.edu.au and John D. Wade; john.wade@florey.edu.au

Received 9 September 2014; Accepted 11 October 2014

Academic Editor: Andrei Surguchov

Copyright ( $\odot 2015$ Vinojini B. Nair et al. This is an open access article distributed under the Creative Commons Attribution License, which permits unrestricted use, distribution, and reproduction in any medium, provided the original work is properly cited.

Human (H2) relaxin is a two-chain peptide member of the insulin superfamily and possesses potent pleiotropic roles including regulation of connective tissue remodeling and systemic and renal vasodilation. These effects are mediated through interaction with its cognate G-protein-coupled receptor, RXFP1. H2 relaxin recently passed Phase III clinical trials for the treatment of congestive heart failure. However, its in vivo half-life is short due to its susceptibility to proteolytic degradation and renal clearance. To increase its residence time, a covalent dimer of $\mathrm{H} 2$ relaxin was designed and assembled through solid phase synthesis of the two chains, including a judiciously monoalkyne sited B-chain, followed by their combination through regioselective disulfide bond formation. Use of a bisazido $\mathrm{PEG}_{7}$ linker and "click" chemistry afforded a dimeric $\mathrm{H} 2$ relaxin with its active site structurally unhindered. The resulting peptide possessed a similar secondary structure to the native monomeric $\mathrm{H} 2$ relaxin and bound to and activated RXFP1 equally well. It had fewer propensities to activate RXFP2, the receptor for the related insulin-like peptide 3. In human serum, the dimer had a modestly increased half-life compared to the monomeric $\mathrm{H} 2$ relaxin suggesting that additional oligomerization may be a viable strategy for producing longer acting variants of $\mathrm{H} 2$ relaxin.

\section{Introduction}

Relaxin, one of the first hormones to be discovered, is a member of the insulin superfamily of peptides [1]. It is a small two-chain, three-disulfide bonded peptide $[2,3]$. Once much ignored by the international research community [4], relaxin, similar to its sister hormones insulin and the insulinlike growth factors (IGFs), is now known as a multifunctional hormone. It is primarily involved with the maintenance of reproduction and pregnancy and in the facilitation of the delivery of the young. Its native G-protein-coupled receptor, relaxin family peptide receptor 1 [5], RXFP1 (previously known as LGR7), was shown to be widely distributed in various organs in both males and females. Human (H2) relaxin, the major stored and circulating form of human relaxin, is now known to play a key role in inflammatory and matrix remodeling processes and possesses potent vasodilatory, angiogenic, and other cardioprotective actions $[6,7]$.

At physiological concentrations, the $\mathrm{H} 2$ relaxin exists as a monomer [3]. However, Eigenbrot et al. reported the crystal structure for $\mathrm{H} 2$ relaxin and showed that it exists as a noncovalent dimer [8]. This was confirmed by sedimentation equilibrium analytical ultra-centrifugation studies [9]. This probably corresponds to the stored form of $\mathrm{H} 2$ relaxin and such a dimer is likely to be biologically inactive because the known key receptor binding residues $\left(\mathrm{R}^{\mathrm{B} 13}, \mathrm{R}^{\mathrm{B} 17}\right.$, and $\left.\mathrm{I}^{\mathrm{B} 20}\right)$ in $\mathrm{H} 2$ relaxin $[2,7]$ form part of the dimer interface [8]. This is supported by the fact that the monomer of the related peptide, 
insulin, is involved in its tyrosine kinase receptor activation whereas its dimeric and hexameric forms are involved in stabilizing the molecule during storage $[10,11]$. A covalently linked (through a disulfide bridge) dimeric insulin peptide was recently prepared by recombinant DNA technology. It neither bound to the insulin receptor nor induced a metabolic response in vitro [12], which is consistent with the view that the monomeric form is the active form of insulin. However, the insulin dimer was shown to be extremely thermodynamically stable in vitro which highlighted the importance of oligomerization for insulin stability [12]. This suggests that a covalently linked dimeric relaxin may also be more stable in vitro as well as in vivo compared to its monomeric form. Such a compound, if it retained biological activity, would be very valuable given that $\mathrm{H} 2$ relaxin recently passed Phase III clinical trials for treating acute heart failure [13] despite having a short in vivo half-life of approximately $10 \mathrm{~min}[14,15]$ that is characteristic of many peptides and proteins. It is for this reason that $\mathrm{H} 2$ relaxin requires continuous intravenous infusion into patients over 48 hours [13]. Therefore, there is a clear need for improving the pharmacokinetic properties of $\mathrm{H} 2$ relaxin in order to potentially improve its therapeutic value.

In this study, we undertook to design and develop a covalently linked dimeric analogue of synthetic $\mathrm{H} 2$ relaxin using both click chemistry and a small polyethylene glycol (PEG) spacer to link the two monomers in such a structural orientation so as to retain biological activity (Figure 1). We studied its structural and functional role using circular dichroism (CD) spectroscopy and RXFP1- and RXFP2-expressing cells, respectively. It was shown that the dimeric $\mathrm{H} 2$ relaxin possessed a high degree of secondary structural similarity to native $\mathrm{H} 2$ relaxin. Importantly, unlike the insulin dimer, the dimeric $\mathrm{H} 2$ relaxin is equipotent to native $\mathrm{H} 2$ relaxin monomer and exhibits improved in vitro serum stability.

\section{Experimental Procedures}

2.1. Materials. 9-Fluorenylmethoxycarbonyl- (Fmoc-) protected L- $\alpha$-amino acids and 1-[bis(dimethylamino)methylene]-1H-benzotriazolium hexafluorophosphate 3-oxide (HBTU) were purchased from GL Biochem (Shanghai, China). N,N-Dimethylformamide (DMF), piperidine, and trifluoroacetic acid (TFA) were obtained from Auspep (Melbourne, Australia). PAL-PEG-PS resins with substitution of ca. $0.20 \mathrm{mmol} / \mathrm{g}$ were purchased from Applied Biosystems Inc. (Melbourne, Australia). Diethyl ether, methanol, acetonitrile, and dichloromethane were purchased from Merck (Melbourne, Australia), trifluoromethanesulfonic acid (TFMSA), anisole, triisopropylsilane (TIPS), 3,6dioxa-1,8-octanedithiol (DODT), and diisopropylethylamine (DIEA) were from Sigma-Aldrich (Sydney, Australia), and 2,2'-dipyridyl disulfide (DPDS) was from Fluka (Switzerland). $\mathrm{CaCl}_{2}$ was purchased from Mallinckrodt (Melbourne, Australia) and $\mathrm{Na}_{2} \mathrm{HPO}_{4}$ and $\mathrm{MgSO}_{4}$ were purchased from $\mathrm{BDH}$ Chemicals while $\mathrm{KH}_{2} \mathrm{PO}_{4}$ and $\mathrm{MnCl}_{2}$ were purchased from Ajax Chemicals (Sydney, Australia). Dulbecco's modified Eagle medium (DMEM), penicillin/streptomycin, L-glutamine, and fetal bovine serum were purchased from Invitrogen (Melbourne, Australia). Sterile-filtered serum from human AB plasma was purchased from Sigma-Aldrich (Sydney, Australia). All other reagents were purchased from Sigma-Aldrich (Sydney, Australia). Native recombinant DNA-derived human relaxin-2 used as control was obtained from Corthera Inc. (San Francisco, CA, a subsidiary of Novartis AG, Basel, Switzerland). Synthetic europium-labelled $\mathrm{H} 2$ relaxin, unlabelled $\mathrm{H} 2$, and human INSL3 were prepared in-house as previously described $[16,17]$.

\subsection{Synthesis}

2.2.1. Chemical Peptide Synthesis. The $\mathrm{H} 2$ relaxin A- and Bchains were assembled as C-terminal amides on an automated Protein Technologies Tribute peptide synthesizer (Tuscan, AZ) or CEM Liberty microwave peptide synthesizer (Ai Scientific, Australia) using Fmoc chemistry. Side chain protecting groups of trifunctional amino acids were TFAlabile, except for tert-butyl- (tBu-) protected cysteine in position A11 and acetamidomethyl- (Acm-) protected cysteines in positions A24 and B23. Using instrument default protocols, both A- and B-chains were separately synthesized either at $0.1 \mathrm{mmol}$ scale or $0.2 \mathrm{mmol}$ scale activated with either 4 - or 5-fold molar excess of HBTU ( 0.4 or $0.5 \mathrm{mmol}$ for a $0.1 \mathrm{mmol}$ scale of resin; $0.8 \mathrm{mmol}$ for a $0.2 \mathrm{mmol}$ scale of resin) in the presence of 5 equivalents DIEA. Resinattached peptides were treated with $20 \% \mathrm{v} / \mathrm{v}$ piperidine/DMF to remove $\mathrm{N}^{\alpha}$-Fmoc protecting groups. When using the microwave synthesizer, coupling and deprotection steps were carried out at $75^{\circ} \mathrm{C}$ and $25 \mathrm{~W}$ microwave power for $5 \mathrm{mins}$ and $60 \mathrm{~W}$ microwave power for 3 mins, respectively, when using the CEM Liberty microwave synthesizer. Coupling and deprotection steps were carried out for 30 and 10 mins, respectively, when using Tribute synthesizers. Upon complete coupling of the final amino acid of the native B-chain peptide sequence, an extra amino acid containing the alkyne group (Fmoc-L-propargylglycine) was coupled by manual coupling procedures.

\subsubsection{Peptide-Resin Cleavage. Upon completion of solid} phase synthesis, the A- and B-chains were cleaved from the solid supports by treatment with TFA containing anisole/TIPS/DODT $(94 \% / 2.5 \% / 2 \% / 1.5 \%, 20 \mathrm{~mL})$ for $2 \mathrm{~h}$. Cleaved products were concentrated by $\mathrm{N}_{2}$ bubbling, precipitated with ice-cold diethyl ether and centrifuged at $3000 \mathrm{rpm}$ for 5 mins. The centrifuged pellet was then washed with icecold diethyl ether and centrifuged. This process was repeated at least three times.

2.2.3. Peptide Purification. All RP-HPLC analytical and purification reactions were monitored using analytical and preparative Vydac C18 columns (pore size, $300 \AA$; particle size $4.6 \times 250 \mathrm{~mm}$ or $22 \times 250 \mathrm{~mm}$, resp.), in a gradient mode with eluant A: $0.1 \%$ aq TFA and eluant B: 0.1\% TFA in acetonitrile.

2.2.4. Preparation of Monoalkyne H2 Relaxin. Following simultaneous cleavage and side chain deprotection and 


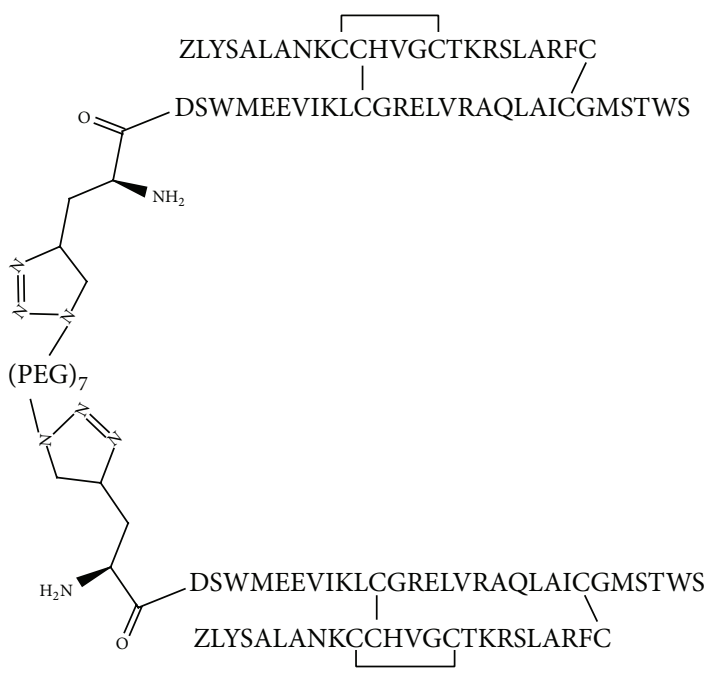

(a)

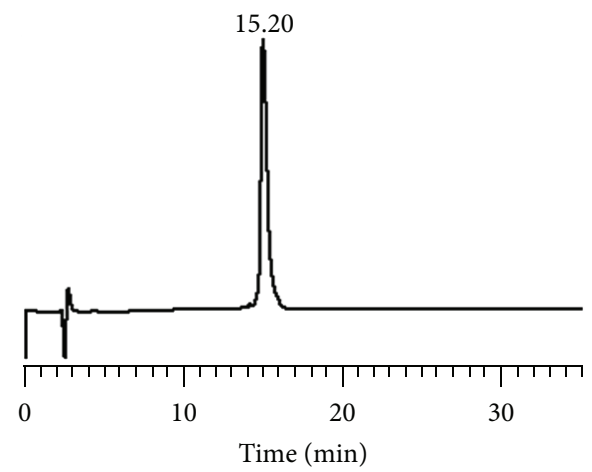

(b)

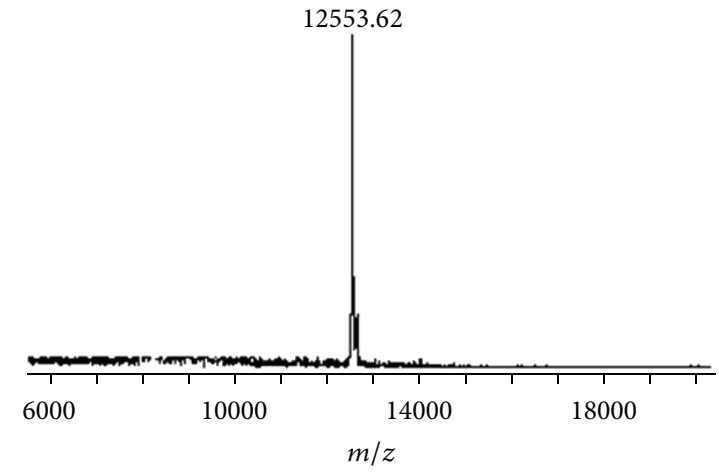

(c)

Figure 1: (a) Primary structure and (b) RP-HPLC and (c) MALDI-TOF MS traces of synthetic H2 (PEG) $)_{7} \mathrm{H} 2$ dimer. Theoretical $[\mathrm{M}+\mathrm{Na}]^{+}$: $12,530.0$.

purification of the crude A- and B-chains, stepwise formation of the three disulfide bonds was carried out via successive oxidation, thiolysis, and iodolysis as previously described [18].

2.2.5. Formation of $\mathrm{H} 2(\mathrm{PEG})_{7} \mathrm{H} 2$ Dimer. $\mathrm{PEG}_{7}$ bisazide (Jena Bioscience, Germany) was coupled onto alkyne $\mathrm{H} 2$ relaxin employing copper-catalyzed click reaction. The alkyne peptide was first dissolved in phosphate buffer saline (PBS) at $\mathrm{pH}$ 7.0. Following this, 0.5 equivalents of $\mathrm{PEG}_{7}$ bisazide and 20 equivalents of aqueous copper (II) sulfate pentahydrate were added sequentially. Finally, 21 equivalents of aqueous ascorbic acid (made up fresh for use) were added and reaction left stirring at room temperature. This reaction progress was monitored by analytical RP-HPLC and stopped after 45 minutes by diluting with approximately $100 \mu \mathrm{L}$ deionised water before RP-HPLC purification.

2.2.6. Peptide Characterization by MALDI-TOF MS. Synthetic peptides (from intermediate steps and final product) were confirmed by matrix-assisted laser desorption ionization time-of-flight mass spectrometry (MALDI-TOF MS) utilizing a Bruker Ultraflex II instrument (Bruker Daltonics,
Bremen, Germany) using sinapinic acid (3,5-dimethoxy-4hydroxycinnamic acid) matrix. This matrix was made up in $70 \%$ acetonitrile containing $0.1 \%$ TFA.

2.2.7. Peptide Quantitation by Amino Acid Analysis. Peptide content and amino acid composition were determined using vapour phase acid hydrolysis in $6 \mathrm{M} \mathrm{HCl} / 2 \%$ phenol at $110^{\circ} \mathrm{C}$ for $24 \mathrm{~h}$. Individual amino acids were converted to stable, fluorescent derivatives using Waters AccQTag kit (Waters, Sydney, Australia). Derivatized amino acids were separated using Shim-Pak XR-ODS $(3 \times 75 \mathrm{~mm}, 2.2 \mu \mathrm{m})$ on Shimadzu RP-HPLC system (Shimadzu, Victoria, Australia).

2.2.8. Secondary Structure Analysis by CD Spectroscopy. A JASCO instrument (J-185, Tokyo, Japan) was utilized to obtain CD spectral analysis of all peptides. The following settings were used to obtain readings: wavelength range 195 to $250 \mathrm{~nm}$, scanning speed $50 \mathrm{~nm} / \mathrm{min}$, bandwidth $0.1 \mathrm{~nm}$, and cell length $1 \mathrm{~mm}$ at $25^{\circ} \mathrm{C}$. The peptide samples were prepared at $0.2 \mu \mathrm{g} / \mu \mathrm{L}$ in $10 \mathrm{mM}$ PBS, $\mathrm{pH}$ 7.4. Raw data from the spectra in millidegree of ellipticity $(\theta)$ were converted to mean residual weight ellipticity (MRE) [19]. 
2.2.9. Receptor Binding Assays. HEK-293T cells stably transfected with RXFP1 grown in DMEM medium supplemented with $10 \% \mathrm{FBS}, 100 \mu \mathrm{g} / \mathrm{mL}$ penicillin, $100 \mu \mathrm{g} / \mathrm{mL}$ streptomycin, and $2 \mathrm{mM}$ L-glutamine were plated out at 40000 cells per well per $200 \mu \mathrm{L}$ in a 96-well ViewPlate with clear bottom and white walls precoated with poly-L-lysine. Competition binding experiments were performed with $5 \mathrm{nM}$ europiumlabelled $\mathrm{H} 2$ relaxin [17] in the absence or presence of increasing concentrations of unlabelled peptides. Nonspecific binding was determined with an excess of unlabelled peptides (500 nM H2 relaxin). Fluorescent measurements were carried out at excitation of $340 \mathrm{~nm}$ and emission of $614 \mathrm{~nm}$ on a Victor Plate reader (Perkin-Elmer, Melbourne, Australia). All data are presented as the mean \pm S.E. of the total specific binding percentage (in triplicate wells), repeated in at least three independent experiments and curves fitted using one-site binding curves in GraphPad Prism 5 (GraphPad Inc., San Diego, CA). Statistical differences in pIC50 values were analyzed using one-way analysis of variance (ANOVA) coupled to a Newman-Keuls multiple comparison test for multiple group comparisons in GraphPad Prism 5.

2.2.10. Functional cAMP Assay. The influence of cAMP signaling by synthetic analogues in HEK-293T cells expressing either human RXFP1 or RXFP2 receptors was assessed using cAMP reporter gene assay as described previously [20]. Briefly, HEK-293T cotransfected with response element pCRE $\beta$-galactosidase reporter plasmid were plated out in Corning Cell BIND 96-well plate at 50000 cells per well per $200 \mu \mathrm{L}$. $24 \mathrm{~h}$ later, cotransfected cells were treated with increasing concentrations of $\mathrm{H} 2$ relaxin analogues in parallel with native $\mathrm{H} 2$ relaxin or human INSL3. After $6 \mathrm{~h}$ incubation at $37^{\circ} \mathrm{C}$, cell media were aspirated and cells were frozen at $-80^{\circ} \mathrm{C}$ overnight. A $\beta$-galactosidase colorimetric assay measuring absorbance at $570 \mathrm{~nm}$ on Benchmark Plus microplate spectrophotometer (Bio-Rad, Gladesville, Australia) was then used to measure relative cAMP responses. Each concentration point was measured in triplicate and each experiment performed independently at least three times. Ligand-induced stimulation of cAMP was expressed as a percentage of the maximum $\mathrm{H} 2$ relaxin response for RXFP1 cells or human INSL3 for RXFP2 cells. GraphPad Prism 5 was used to analyze the cAMP activity assay which was expressed as the mean \pm S.E.M. Statistical analysis was conducted using one-way ANOVA with Newman-Keuls post hoc analysis.

2.2.11. In Vitro Serum Stability. The stability of the synthetic analogue was measured against native $\mathrm{H} 2$ relaxin in human serum. The purchased serum was not heat inactivated in order to retain as much of its proteolytic enzymic activity as possible. The peptides tested were normalized to a final concentration of $1.0 \mathrm{mg} / \mathrm{mL}$ with deionized water, and $10.0 \mu \mathrm{L}$ of peptides was added to $590 \mu \mathrm{L} 100 \%$ human serum. After addition of peptide into the serum, $50 \mu \mathrm{L}$ of samples was removed and quenched with $250 \mu \mathrm{L}$ of ice-cold acetonitrile/ $0.1 \%$ TFA. The solution was then spun down with a benchtop centrifuge at $13,500 \mathrm{rpm}$ (Eppendorf Centrifuge 5804R, Melbourne, Australia) for 15 mins at $4^{\circ} \mathrm{C}$ to pellet the larger, precipitated serum proteins. The remaining peptide/serum solution was placed immediately into $37^{\circ} \mathrm{C}$ incubator. Degradation of peptides was monitored with manual RP-HPLC injections of supernatant using a Phenomenex Aeris Widepore $3.6 \mu \mathrm{m}$ C4 analytical column (pore size, $100 \AA$; particle size 4.6 $\times 250 \mathrm{~mm}$ ), in a stabilized gradient mode with eluent A: $0.1 \%$ aq TFA and eluant B: $0.1 \%$ TFA in acetonitrile. Samples were taken at time points $0.5,1.0,1.5,2.0,2.5,3,4,5$, and $6 \mathrm{~h}$. Each assay was carried out in triplicate. Elution of target peptide was elucidated by retention time analysis and characterization with MALDI-TOF MS at each time point. Kinetic analysis of target peptide at each time point was carried out by least squares analysis of the logarithm of the integration peak area versus retention time. Nonspecific peptide degradation was measured by peptide degradation in serum at $0 \mathrm{~h}$. Correction for serum peptides that might coelute with target peptides was carried out by subtracting integrated peak areas with equivalent serum only solution at all time points (background subtraction). GraphPad Prism 5 was used to analyze the peptide degradation in serum which was expressed as the mean ratio \pm S.E.M. and Microsoft Excel was used to graph all data. Statistical analysis was conducted using one-way ANOVA with Newman-Keuls post hoc analysis.

\section{Results}

The selectively S-protected A- and B-chains were of high purity as determined by analytical RP-HPLC and MALDITOF MS. An Fmoc-propargylglycine was manually coupled onto the $\mathrm{N}$-terminal end of the $\mathrm{B}$-chain prior to cleavage from the solid support and subsequent crude peptide purification. Following this, stepwise regioselective disulfide bond formation between the A-chain and monoalkyne moleculechain was carried out according to established protocols [21-23] to form the two-chain, three-disulfide bond alkyne $\mathrm{H} 2$ relaxin. Copper-catalyzed alkyne-azide cycloaddition was then utilized to "click" two molecules of alkyne-H2 relaxin onto a bisazido PEG, $(\mathrm{PEG})_{7}$, hence forming a dimeric relaxin molecule separated by a short PEG spacer (Figure 2). This was termed $\mathrm{H} 2(\mathrm{PEG})_{7} \mathrm{H} 2$ dimer and was shown to be of high purity as assessed by analytical RP-HPLC and MALDI-TOF MS (Figure 1).

The CD spectra of $\mathrm{H} 2(\mathrm{PEG})_{7} \mathrm{H} 2$ were measured in $10 \mathrm{mM}$ PBS (pH 7.4) buffer (Figure 3). The dimer was found to retain a very similar secondary structure and a high degree of $\alpha$-helical conformation (with pronounced double minima at approximately $208 \mathrm{~nm}$ and $222 \mathrm{~nm}$ ) along with some $\beta$ sheet and random coiled structure. The $\alpha$-helical content of $\mathrm{H} 2$ relaxin was found to be $49 \%$ helicity compared to the $\mathrm{H} 2-\mathrm{PEG}$ dimer with $48 \%$. These values were calculated from the MRE at $222 \mathrm{~nm}$, the $[\theta]_{222}$ values for relaxin and $\mathrm{H} 2$ $(\mathrm{PEG})_{7} \mathrm{H} 2$ dimer being -17511.4 and -17679.4 , respectively. The similarities between the MRE and helix content between these two peptides suggested that the dimer essentially retained native $\mathrm{H} 2$ relaxin-like structure.

To assess the biological activity of the dimer, binding and activity in vitro assays were undertaken in comparison to the native recombinantly produced $\mathrm{H} 2$ relaxin. These assays were 


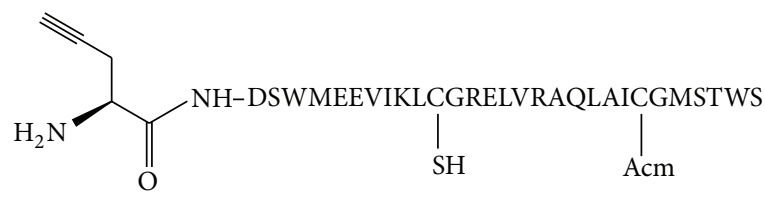

B-chain with propargylglycine attached at the $\mathrm{N}$-terminus
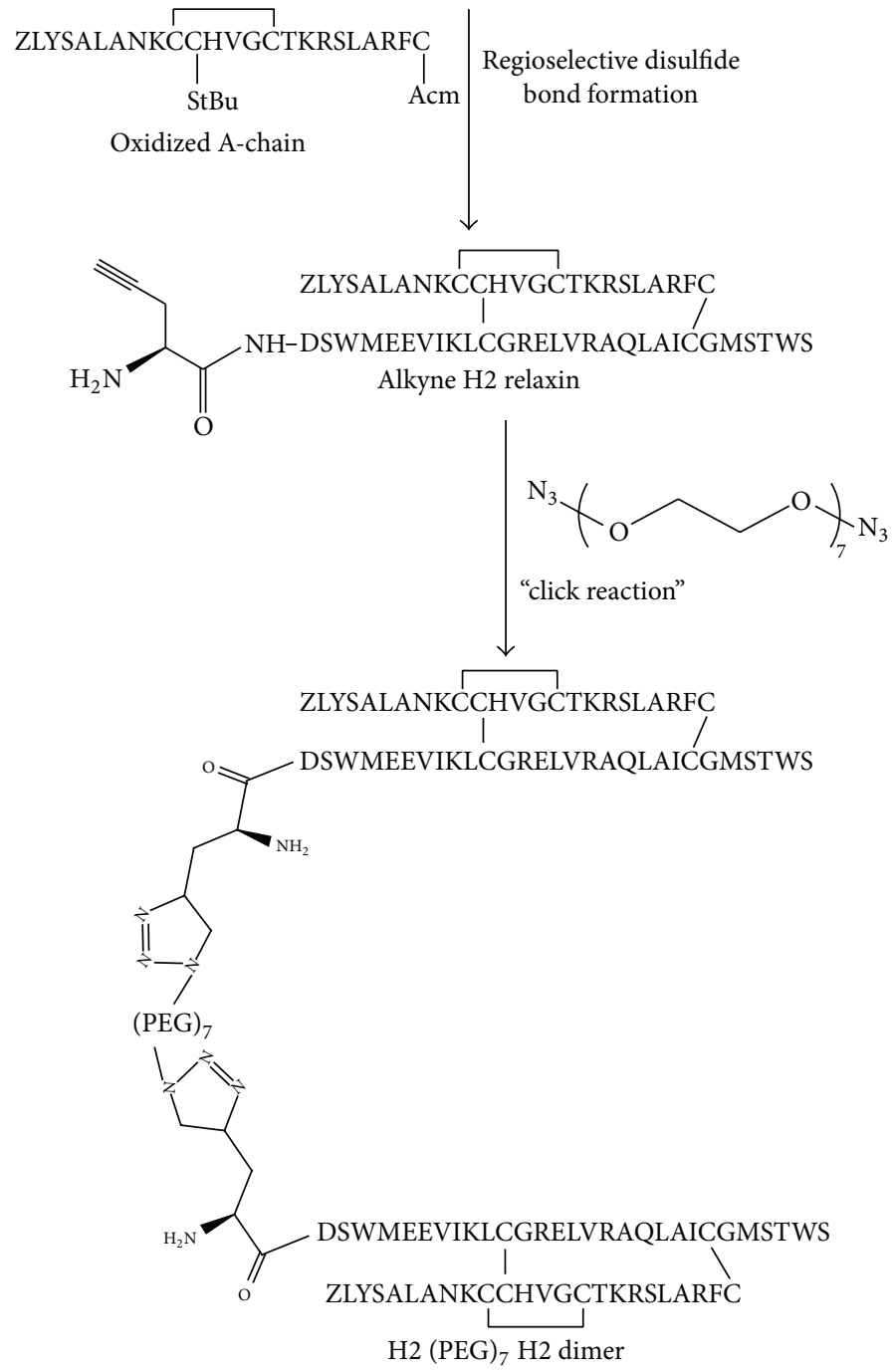

FIGURE 2: Scheme for the preparation of $\mathrm{H} 2(\mathrm{PEG})_{7} \mathrm{H} 2$ dimer by solid phase peptide synthesis and click chemistry.

carried out in HEK-293T cells stably expressing RXFP1, the native receptor of $\mathrm{H} 2$ relaxin. The starting alkyne $\mathrm{H} 2$-relaxin was also assessed for binding and signaling through the RXFP1 and RXFP2 receptor. This was performed to confirm that the disulfide bonds within the two monomeric analogues were assembled in the correct form as other combinations of disulfide pairings have previously been shown to result in no interaction with the RXFP1 receptor (neither binding nor activity) [24]. Following confirmation of the alkyne monomer possessing full $\mathrm{H} 2$ relaxin-like activity (data not shown), the $\mathrm{H} 2$ (PEG) ${ }_{7} \mathrm{H} 2$ dimer was tested for binding and cAMP activity on the same HEK-293T cells expressing
RXFP1. It was found to have similar affinity and potency to $\mathrm{H} 2$ relaxin at the RXFP1 receptor (Figures 4(a) and 4(b)). The dimer was then also tested with RXFP2, the native receptor for INSL3. Interestingly, the peptide displayed significantly weaker activation propensity (Figure 5).

The degradation kinetics and serum stability of the synthetic $\mathrm{H} 2(\mathrm{PEG})_{7} \mathrm{H} 2$ dimer was measured against native $\mathrm{H} 2$ relaxin in male human serum (Figure 6). The purchased serum was not heat inactivated in order to retain as much activity of its proteolytic enzymes and other reductants as possible. This provided a better representation of human serum and a direct in vitro measurement in an experimental 


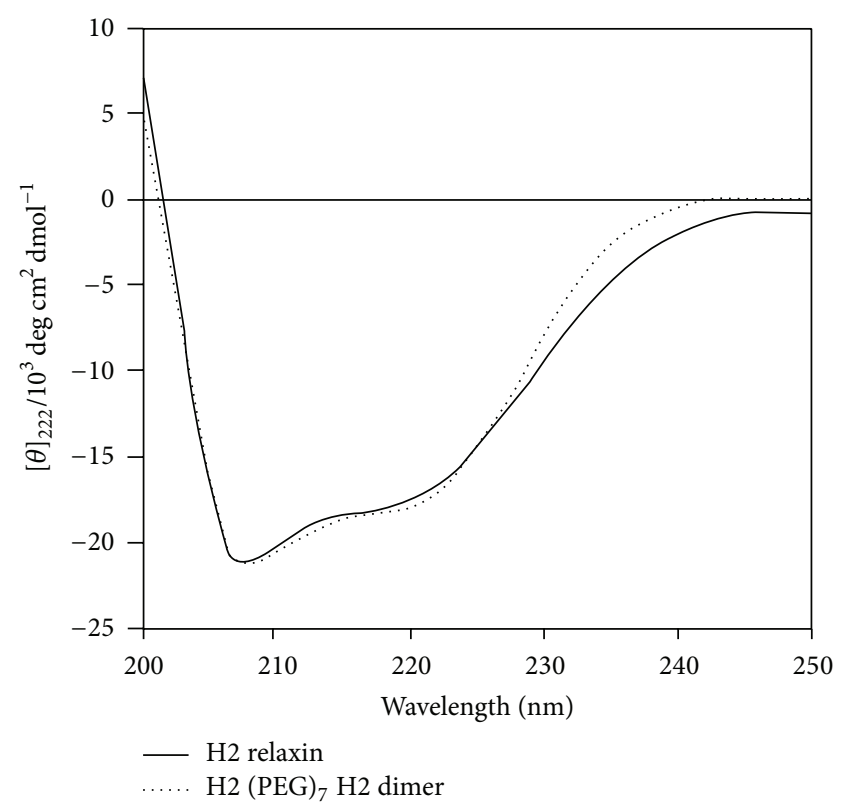

FIgUre 3: CD spectroscopic data of the $\mathrm{H} 2(\mathrm{PEG})_{7} \mathrm{H} 2$ dimer in comparison with native $\mathrm{H} 2$ relaxin.

setting of the degradation kinetics of the relaxin dimer when compared to native relaxin. The $\mathrm{H} 2(\mathrm{PEG})_{7} \mathrm{H} 2$ dimer was observed to retain its original dimeric form in vitro with a half-life of $2.52 \mathrm{hrs}$, significantly longer when compared to native relaxin with $2.22 \mathrm{hrs}$.

\section{Discussion}

Nearly 9 decades since its discovery, the pleotropic peptide $\mathrm{H} 2$ relaxin recently completed a successful Phase III clinical trial for the treatment of acute heart failure [13, 25]. Despite this important success, the short in vivo half-life of the peptide (10 mins) [14, 15] necessitates its continuous intravenous infusion for optimum activity. As the in vivo half-life of a peptide or protein is affected by both its degradation by enzymes and renal clearance [26, 27], it can be improved by, for example, conjugation with large MW compounds such as PEG or by polymerization/aggregation which acts to (at least partially) shield it from proteolytic enzymes and also by slowing clearance, although best results for the latter occur with a molecular mass of greater than $40 \mathrm{kDa}$ [26]. Conjugation of PEG molecules to protein-based biopharmaceuticals has recently proved highly successful in increasing their therapeutic index and clinical use [28]. For example, a combinational treatment of PEGylated $\alpha-2$ interferon and ribavirin has successfully eradicated hepatitis $\mathrm{C}$ virus in approximately $50 \%$ of the treated patients, leading to several PEG-based proteins being approved for therapeutic purposes [29]. PEG moieties are also highly hydrated, hence increasing the hydrodynamic radius of the conjugates and correspondingly improving solubility and reducing urinary glomerular filtration rate [30]. However, such modifications are not without disadvantages. The polydispersity of PEG can

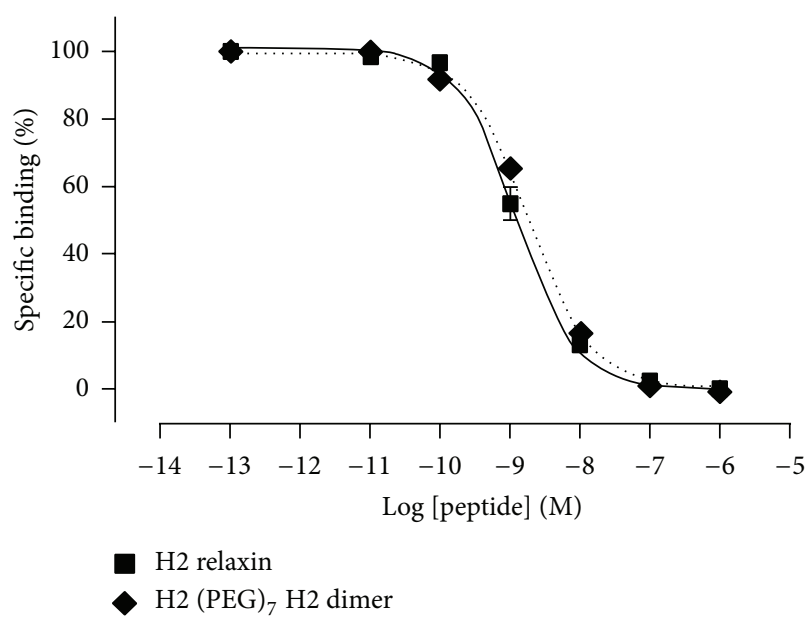

(a) RXFP1 Eu-H2 binding

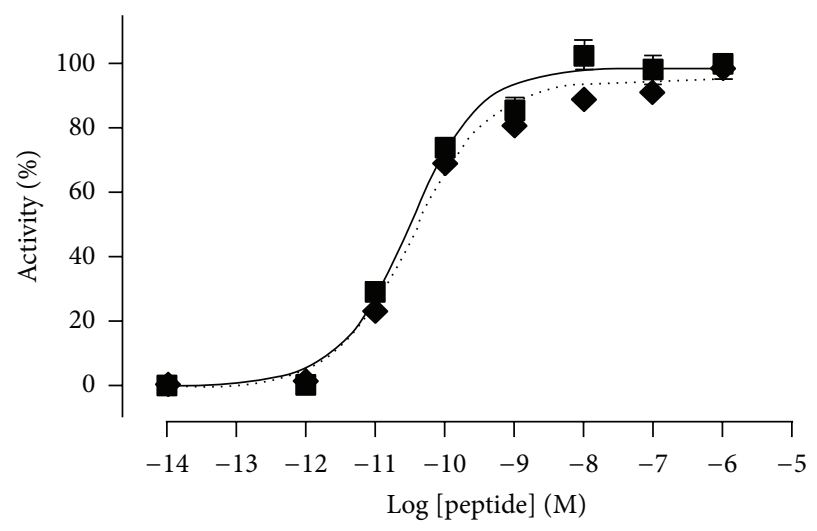

$\mathrm{H} 2$ relaxin

$\mathrm{H} 2(\mathrm{PEG})_{7} \mathrm{H} 2$ dimer

(b) RXFP1 cAMP activity

FIGURE 4: Binding and activity of synthetic $\mathrm{H} 2(\mathrm{PEG})_{7} \mathrm{H} 2$ dimer in comparison to native $\mathrm{H} 2$. (a) Competition binding of $\mathrm{H} 2(\mathrm{PEG})_{7} \mathrm{H} 2$ dimer with europium-labeled $\mathrm{H} 2$ relaxin in HEK-293T cells stably expressing RXFP1. (b) cAMP activity in RXFP1 expressing HEK293 T cells using a pCRE- $\beta$-galactosidase reporter gene system. Data are expressed as percentage of cAMP response and are pooled data from at least three independent experiments performed in triplicate.

complicate accurate quality control as well as introducing physicochemical property modifications that make chemical characterization by RP-HPLC and MS extremely challenging due to peak broadening, even disappearance, and a lack of ionization. For this reason, oligomerization strategies are gaining increasing attention as a means of increasing in vivo stability [31]. A dimeric erythropoietin formed by chemical crosslinking of the monomer showed an increased plasma half-life in rabbits of more than $24 \mathrm{~h}$ compared to the monomer's $4 \mathrm{~h}$. The dimer also possessed 26 -fold higher activity in vivo [32]. A dimer of the antibacterial peptide, A3-APO, possessed a substantially increased serum half-life (100 $\mathrm{min})$ compared to the monomer $(4 \mathrm{~min})$ [33]. For this reason, we undertook to examine the feasibility of developing a synthetic dimer of $\mathrm{H} 2$ relaxin as a first step towards 


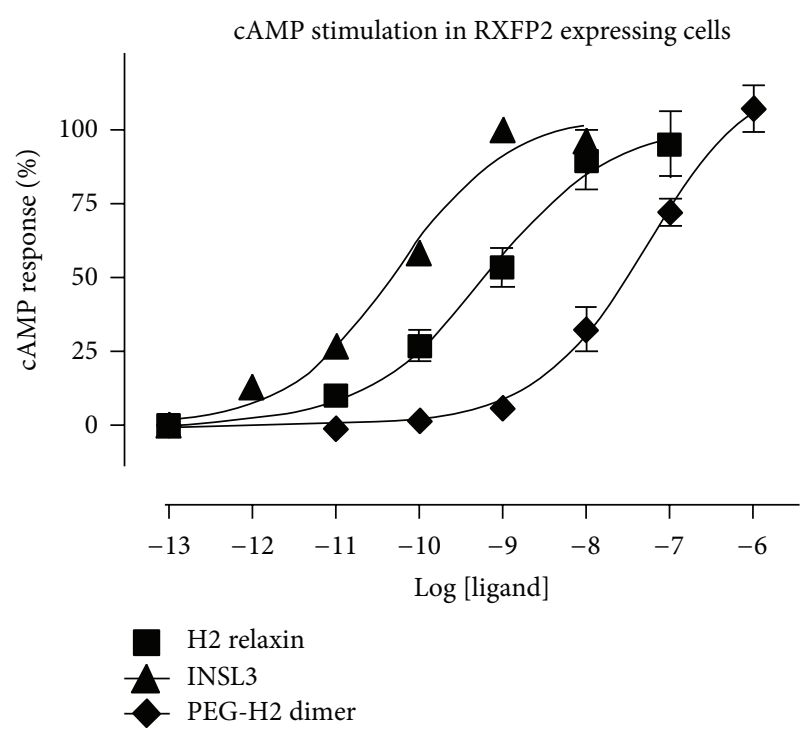

FIGURE 5: cAMP activity in RXFP2 expressing HEK-293T cells using a pCRE- $\beta$-galactosidase reporter gene system. Data are expressed as percentage of CAMP response and are pooled data from at least three independent experiments performed in triplicate.

obtaining improved pharmacokinetics. This was designed and assembled using a bisazido $\mathrm{PEG}_{7}$ moiety between two molecules of synthetic functionalized $\mathrm{H} 2$ relaxin via click chemistry. This linker was chosen because it is sufficiently longer to space the two peptide units apart and also because it is monodisperse thus simplifying characterization. Our previous studies have shown that the $\mathrm{N}$-terminus of the $\mathrm{B}$ chain can be truncated by six residues [34] or modified to accommodate a functional moiety such as a biotin [35] or large fluorophore [18] without significant loss of activity. This is because this site is far from its primary active site which consists of the B-chain $\mathrm{C}$-terminal $\alpha$-helical region [2]. Consequently, the bisazido $\mathrm{PEG}_{7}$ moiety was conjugated at both its ends with $\mathrm{N}$-terminal B-chain alkyne $\mathrm{H} 2$ relaxin employing the now well-established click reaction.

The $\mathrm{CD}$ spectral data showed that $\mathrm{H} 2(\mathrm{PEG})_{7} \mathrm{H} 2$ dimer had a comparable secondary structure to native $\mathrm{H} 2$ relaxin (Figure 3), strongly suggesting that the dimeric form of $\mathrm{H} 2$ relaxin has native relaxin-like structural integrity. Further evidence was also provided by the near-native RXFP1 receptor binding and activation activity (Figure 4). This result confirmed that the presentation of the active site of $\mathrm{H} 2$ relaxin is essentially unaffected by the tethering of the molecule to the $\mathrm{PEG}_{7}$ linker via the $\mathrm{N}$-terminus of the $\mathrm{B}$-chain. This is reflected by the in vitro RXFP1 binding and cAMP data in that despite the dimer being at least twice the molecular size of native relaxin, its size and spacer length did not impair the ability of the dimer to bind and activate downstream RXFP1 signaling. The RXFP1 binding domain within the Bchain of the dimer was still exposed and able to interact with the receptors, akin to native relaxin. This observation is consistent with previous work where prorelaxin with its C-chain intact was still able to interact and signal through the RXFP1 receptor [36, 37]. Interestingly and positively,

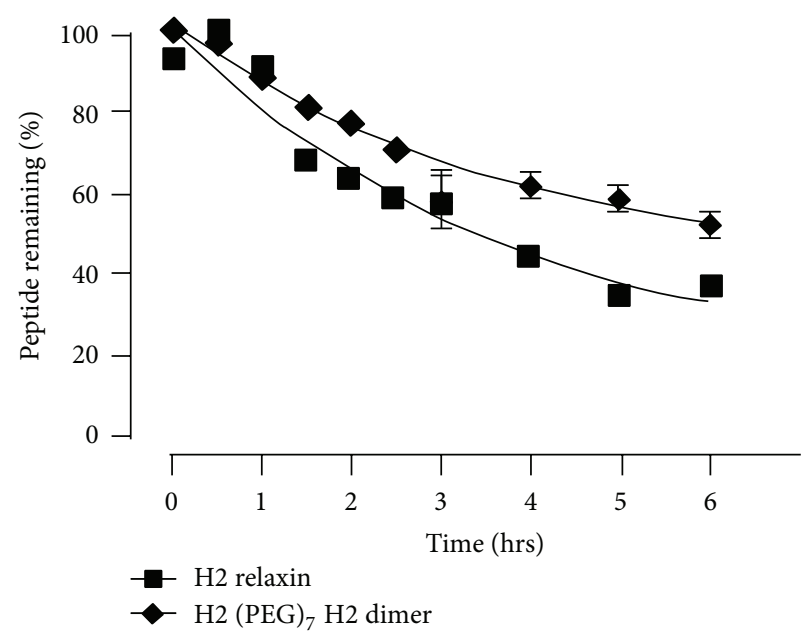

(a)

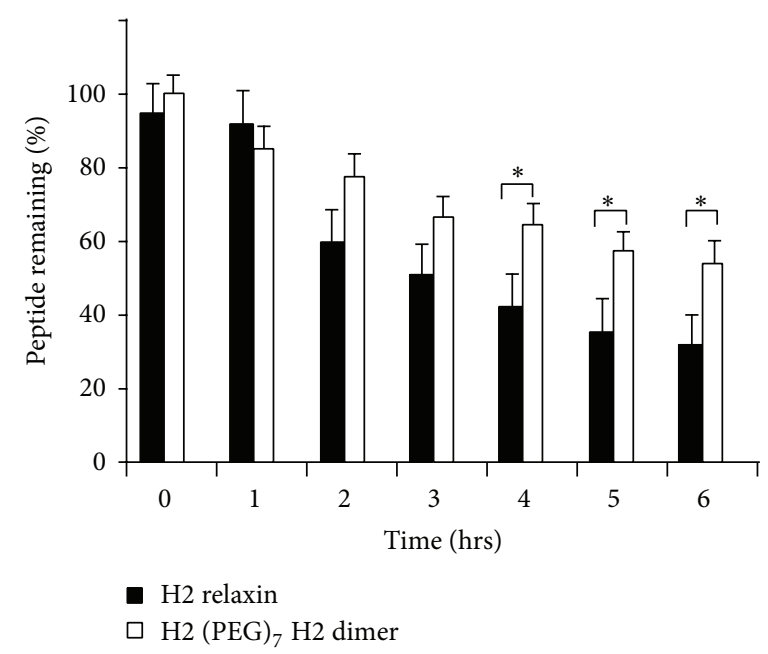

(b)

FIGURE 6: In vitro serum stability analysis. (a) Curve: half-life determination of $\mathrm{H} 2(\mathrm{PEG})_{7} \mathrm{H} 2$ dimer when compared to $\mathrm{H} 2$ relaxin incubated in vitro at $37^{\circ} \mathrm{C}$ in human male serum. (b) Bar graph: comparison of peptide degradation at different time points. ${ }^{*} P<0.05$.

at RXFP2, the receptor for the related peptide insulin-like peptide 3 , the dimer was significantly less active than $\mathrm{H} 2$ relaxin itself (Figure 5).

Importantly, in the in vitro serum stability assay, the $\mathrm{H} 2(\mathrm{PEG})_{7} \mathrm{H} 2$ dimer had an improved increase in its halflife compared to the native $\mathrm{H} 2$ relaxin (Figures 6(a) and $6(\mathrm{~b})$ ), which is probably due to increased molecular shielding. However, as evidenced by the disparity between the in vitro serum half-life (ca. $2 \mathrm{~h}$; this study) and reported in vivo half-life (a few minutes $[14,15]$ ) of native $\mathrm{H} 2$ relaxin, it is clear that renal clearance is a greater issue. It remains to be determined if the increased hydrodynamic volume due to the larger molecular weight of the $\mathrm{H} 2$ relaxin dimer will also result in a moderation of its renal clearance. Past experience suggests that this will be the case [33]. Indeed, it was also recently shown that a covalent dimer of exendin- 4 had 2.7 
times greater increased biological half-life over the native monomer [38].

In conclusion, efficient solid phase peptide synthesis in combination with click chemistry techniques was used to successfully prepare a structurally well-defined homodimer of $\mathrm{H} 2$ relaxin, $\mathrm{H} 2(\mathrm{PEG})_{7} \mathrm{H} 2$. This peptide was shown to possess increased in vitro serum stability compared to native $\mathrm{H} 2$ relaxin whilst retaining relaxin-like binding affinity, activity, and structural integrity in vitro. The dimer peptide also has the potential to slow urinary glomerular filtration rate [30] which will be investigated in the future. Similar approaches can be adopted for the preparation of further increased multimeric forms of $\mathrm{H} 2$ relaxin using, for example, a benzene core bearing three or more azido moieties [39] or short PEG-linked dendrons [31].

\section{Conflict of Interests}

The authors declare that there is no conflict of interests regarding the publication of this paper.

\section{Authors' Contribution}

Mohammed Akhter Hossain and John D. Wade conceived and designed the experiments. Vinojini B. Nair performed the experiments. Ross A. D. Bathgate and Chrishan S. Samuel analyzed the data. Mohammed Akhter Hossain, Frances Separovic, Ross A. D. Bathgate, and John D. Wade contributed reagents/materials/analysis tools. Vinojini B. Nair, Mohammed Akhter Hossain, Frances Separovic, and John D. Wade wrote the paper. Mohammed Akhter Hossain and John D. Wade equally contributed in the paper.

\section{Acknowledgments}

This research was partially funded by National Health and Medical Research Council (NHMRC) of Australia Project Grants 508995 and 1023078 to John D. Wade, Mohammed Akhter Hossain, and Ross A. D. Bathgate. The authors thank Tania Ferraro and Sharon Layfield for their assistance in undertaking the biological assays. Mohammed Akhter Hossain was the recipient of a Florey Foundation Fellowship and Ross A. D. Bathgate (APP1042650) and Chrishan S. Samuel (APP1041766) are NHMRC Senior Research Fellows, and John D. Wade (APP5018148) is an NHMRC Principal Research Fellow. Research at The Florey Institute of Neuroscience and Mental Health is supported by the Victorian Government Operational Infrastructure Support Program.

\section{References}

[1] F. L. Hisaw, "Experimental relaxation of the pubic ligament of the guinea-pig," Proceedings of the Society for Experimental Biology and Medicine, vol. 23, pp. 611-613, 1926.

[2] M. A. Hossain and J. D. Wade, "The roles of the A- and B-chains of human relaxin-2 and -3 on their biological activity," Current Protein and Peptide Science, vol. 11, no. 8, pp. 719-724, 2010.

[3] R. A. D. Bathgate, M. L. Halls, E. T. van der Westhuizen, G. E. Callander, M. Kocan, and R. J. Summers, "Relaxin family peptides and their receptors," Physiological Reviews, vol. 93, no. 1, pp. 405-480, 2013.

[4] G. D. Bryant-Greenwood, "Relaxin as a new hormone," Endocrine Reviews, vol. 3, no. 1, pp. 62-90, 1982.

[5] R. A. Bathgate, R. Ivell, B. M. Sanborn, O. D. Sherwood, and R. J. Summers, "International union of pharmacology LVII: recommendations for the nomenclature of receptors for relaxin family peptides," Pharmacological Reviews, vol. 58, no. 1, pp. 731, 2006.

[6] X.-J. Du, R. A. D. Bathgate, C. S. Samuel, A. M. Dart, and R. J. Summers, "Cardiovascular effects of relaxin: from basic science to clinical therapy," Nature Reviews Cardiology, vol. 7, no. 1, pp. 48-58, 2010.

[7] F. Shabanpoor, F. Separovic, and J. D. Wade, "The human insulin superfamily of polypeptide hormones," Vitamins and Hormones, vol. 80, pp. 1-31, 2009.

[8] C. Eigenbrot, M. Randal, C. Quan, J. Burnier, L. O'Connell, and E. A. A. Rinderknecht Kossiakoff, "X-ray structure of human relaxin at 1.5 A," Journal of Molecular Biology, vol. 221, no. 1, pp. $15-21,1991$.

[9] S. J. Shire, L. A. Holladay, and E. Rinderknecht, "Self-association of human and porcine relaxin as assessed by analytical ultracentrifugation and circular dichroism," Biochemistry, vol. 30, no. 31, pp. 7703-7711, 1991.

[10] K. Huus, S. Havelund, H. B. Olsen, M. Van De Weert, and S. Frokjaer, "Thermal dissociation and unfolding of insulin," Biochemistry, vol. 44, no. 33, pp. 11171-11177, 2005.

[11] J. Brange and L. Langkjoer, "Insulin structure and stability," Pharmaceutical biotechnology, vol. 5, pp. 315-350, 1993.

[12] T. N. Vinther, M. Norrman, H. M. Strauss et al., "Novel covalently linked insulin dimer engineered to investigate the function of insulin dimerization," PLOS ONE, vol. 7, no. 2, Article ID e30882, 2012.

[13] J. R. Teerlink, G. Cotter, B. A. Davison et al., "Serelaxin, recombinant human relaxin-2, for treatment of acute heart failure (RELAX-AHF): a randomised placebo-controlled trial," The Lancet, vol. 381, no. 9860, pp. 29-39, 2013.

[14] S. A. Chen, A. J. Perlman, N. Spanski et al., “The pharmacokinetics of recombinant human relaxin in nonpregnant women after intravenous, intravaginal, and intracervical administration," Pharmaceutical Research, vol. 10, no. 6, pp. 834-838, 1993.

[15] S. A. Chen, B. Reed, T. Nguyen, N. Gaylord, G. B. Fuller, and J. Mordenti, "The pharmacokinetics and absorption of recombinant human relaxin in nonpregnant rabbits and rhesus monkeys after intravenous and intravaginal administration," Pharmaceutical Research, vol. 10, no. 2, pp. 223-227, 1993.

[16] C. S. Samuel, F. Lin, M. A. Hossain et al., "Improved chemical synthesis and demonstration of the relaxin receptor binding affinity and biological activity of mouse relaxin," Biochemistry, vol. 46, no. 18, pp. 5374-5381, 2007.

[17] F. Shabanpoor, R. A. D. Bathgate, A. Belgi et al., "Site-specific conjugation of a lanthanide chelator and its effects on the chemical synthesis and receptor binding affinity of human relaxin-2 hormone," Biochemical and Biophysical Research Communications, vol. 420, no. 2, pp. 253-256, 2012.

[18] L. J. Chan, C. M. Smith, B. E. Chua et al., "Synthesis of fluorescent analogs of relaxin family peptides and their preliminary in vitro and in vivo characterization," Frontiers in Chemistry, vol. 1, article 30, 2013.

[19] L. V. Najbar, D. J. Craik, J. D. Wade, D. Salvatore, and M. J. McLeish, "Conformational analysis of LYS(11-36), a peptide 
derived from the $\beta$ - sheet region of T4 lysozyme, in TFE and SDS," Biochemistry, vol. 36, no. 38, pp. 11525-11533, 1997.

[20] P. G. Scott, C. M. Dodd, E. M. Bergmann, J. K. Sheehan, and P. N. Bishop, "Crystal structure of the biglycan dimer and evidence that dimerization is essential for folding and stability of class I small leucine-rich repeat proteoglycans," Journal of Biological Chemistry, vol. 281, no. 19, pp. 13324-13332, 2006.

[21] M. A. Hossain, A. Belgi, F. Lin et al., "Use of a temporary "solubilizing" peptide tag for the Fmoc solid-phase synthesis of human insulin glargine via use of regioselective disulfide bond formation," Bioconjugate Chemistry, vol. 20, no. 7, pp.1390-1396, 2009.

[22] M. A. Hossain, R. A. D. Bathgate, C. K. Kong et al., "Synthesis, conformation, and activity of human insulin-like peptide 5 (INSL5)," ChemBioChem, vol. 9, no. 11, pp. 1816-1822, 2008.

[23] M. A. Hossain, K. J. Rosengren, S. Zhang et al., "Solid phase synthesis and structural analysis of novel A-chain dicarba analogs of human relaxin-3 (INSL7) that exhibit full biological activity," Organic and Biomolecular Chemistry, vol. 7, no. 8, pp. 1547-1553, 2009.

[24] M. P. Del Borgo, R. A. Hughes, and J. D. Wade, "Conformationally constrained single-chain peptide mimics of relaxin B-chain secondary structure," Journal of Peptide Science, vol. 11, no. 9, pp. 564-571, 2005.

[25] J. R. Teerlink, M. Metra, G. M. Felker et al., "Relaxin for the treatment of patients with acute heart failure (Pre-RELAXAHF): a multicentre, randomised, placebo-controlled, parallelgroup, dose-finding phase IIb study," The Lancet, vol. 373, no. 9673, pp. 1429-1439, 2009.

[26] M. Werle and A. Bernkop-Schnürch, "Strategies to improve plasma half life time of peptide and protein drugs," Amino Acids, vol. 30, no. 4, pp. 351-367, 2006.

[27] L. Otvos and J. D. Wade, "Current challenges in peptide-based drug discovery," Frontiers in Chemistry, vol. 2, article 62, 2014.

[28] M. W. Fried, M. L. Shiffman, K. Rajender Reddy et al., "Peginterferon alfa-2a plus ribavirin for chronic hepatitis C virus infection," The New England Journal of Medicine, vol. 347, no. 13, pp. 975-982, 2002.

[29] J. M. Harris and R. B. Chess, "Effect of pegylation on pharmaceuticals," Nature Reviews Drug Discovery, vol. 2, no. 3, pp. 214221, 2003.

[30] P. Caliceti and F. M. Veronese, "Pharmacokinetic and biodistribution properties of poly(ethylene glycol)-protein conjugates," Advanced Drug Delivery Reviews, vol. 55, no. 10, pp. 1261-1277, 2003.

[31] E. R. Gillies and J. M. J. Frechet, "Dendrimers and dendritic polymers in drug delivery," Drug Discovery Today, vol. 10, no. 1, pp. 35-43, 2005.

[32] A. J. Sytkowski, E. D. Lunn, K. L. Davis, L. Feldman, and S. Siekman, "Human erythropoietin dimers with markedly enhanced in vivo activity," Proceedings of the National Academy of Sciences of the United States of America, vol. 95, no. 3, pp. 1184$1188,1998$.

[33] P. B. Noto, G. Abbadessa, M. Cassone et al., "Alternative stabilities of a proline-rich antibacterial peptide in vitro and in vivo," Protein Science, vol. 17, no. 7, pp. 1249-1255, 2008.

[34] M. A. Hossain, K. J. Rosengren, C. S. Samuel et al., "The minimal active structure of human relaxin-2," Journal of Biological Chemistry, vol. 286, no. 43, pp. 37555-37565, 2011.
[35] M. N. Mathieu, J. D. Wade, G. W. Tregear et al., "Synthesis, conformational studies and biological activity of $\mathrm{N} \alpha$-monobiotinylated rat relaxin," Journal of Peptide Research, vol. 57, no. 5, pp. 374-382, 2001.

[36] R. A. Bathgate, A. Hsueh, and O. D. Sherwood, "Physiology and molecular biology of the relaxin peptide family," in Knobil and Neill's Physiology of Reproduction, J. D. Neill, Ed., pp. 679-768, Academic Press, San Diego, Calif, USA, 2006.

[37] M. A. Hossain, C. S. Samuel, C. Binder et al., "The chemically synthesized human relaxin-2 analog, B-R13/17K H2, is an RXFP1 antagonist," Amino Acids, vol. 39, no. 2, pp. 409-416, 2010.

[38] T. H. Kim, H. H. Jiang, S. Lee et al., "Mono-PEGylated dimeric exendin-4 as high receptor binding and long-acting conjugates for type 2 anti-diabetes therapeutics," Bioconjugate Chemistry, vol. 22, no. 4, pp. 625-632, 2011.

[39] C. Heinis, T. Rutherford, S. Freund, and G. Winter, "Phageencoded combinatorial chemical libraries based on bicyclic peptides," Nature Chemical Biology, vol. 5, no. 7, pp. 502-507, 2009. 

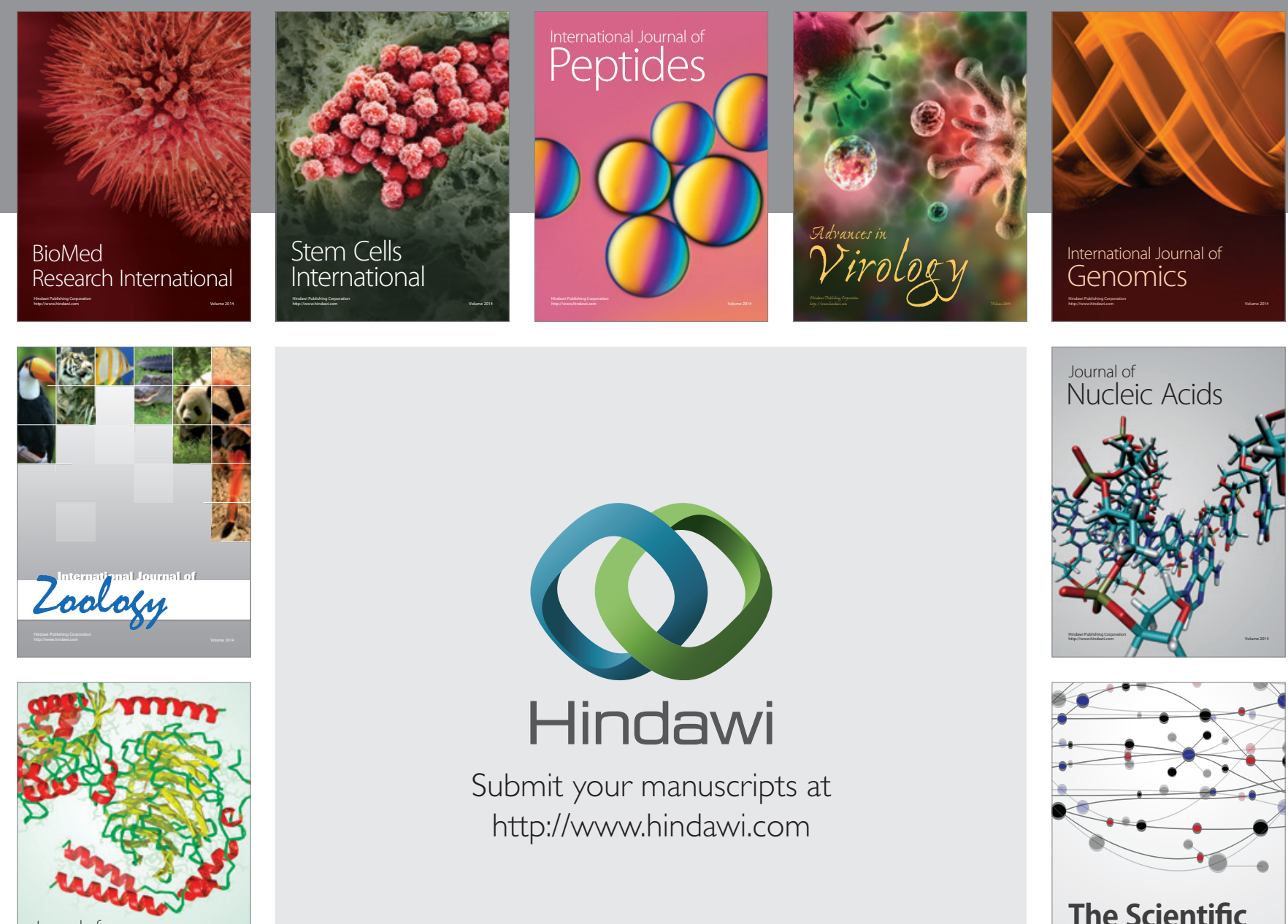

Submit your manuscripts at

http://www.hindawi.com

Journal of
Signal Transduction
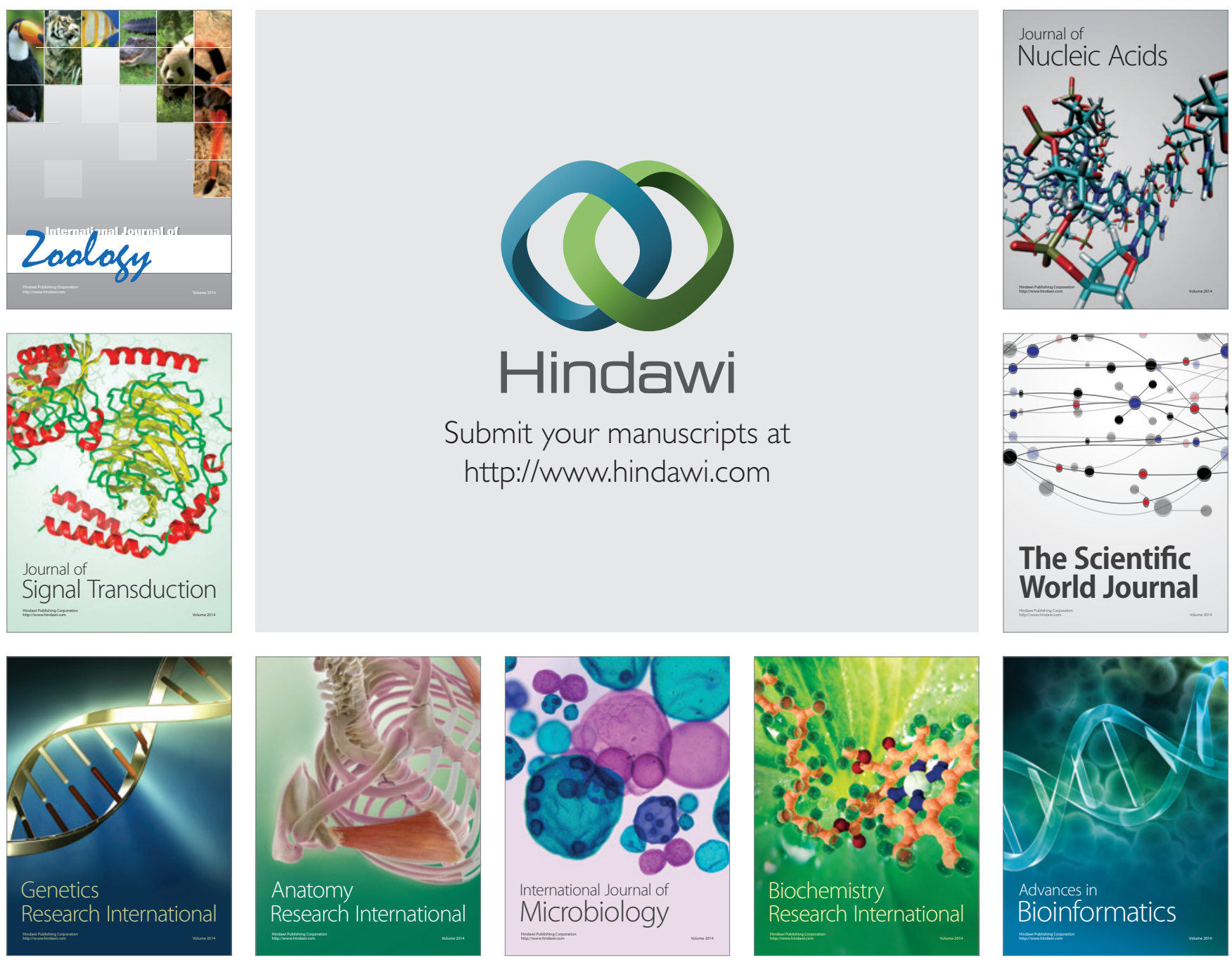

The Scientific World Journal
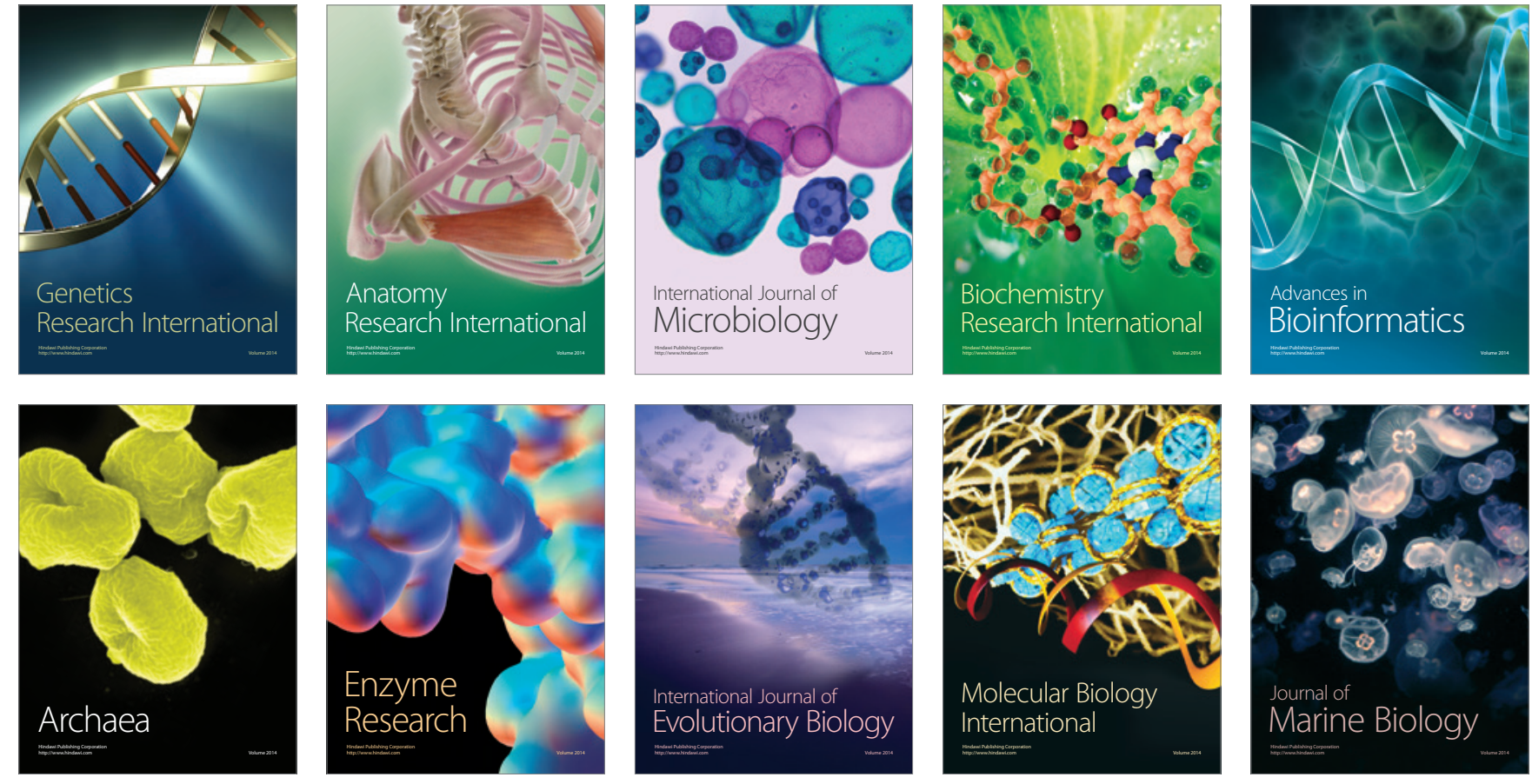